\title{
Introduction: The Language and Culture Perspective in Employee Relations
}

\section{Karl Koch and Pietro Manzella}

The book provides an insight into the deeper structures underlying the similarities and differences in Employee Relations Systems by synthesis of cultural, language and specific employee relations factors. Enabling the understanding of those involved in international and comparative employee relations matters in a more insightful way than current approaches. It also intends to facilitate a holistic approach to translations, and understanding, of employee relationsfocused texts. One of the central issues is that translations, understandings, in specific contexts, such as labor law, employee relevant technical matters, in areas as, for example, collective bargaining and arbitration processes, achieve clarity through the inclusion of cultural characteristics.

The book, therefore, includes an in-depth explanation and analysis of specific and general concepts of employee relations within this contextual field. It identifies examples of how cultural identification shapes, directs and influences distinctive systems of employee relations-moving toward a translation objective which is anchored in a holistic approach providing a deeper understanding of the subject matter.

Employee Relations have been subject to enormous changes over the last decades with the impact of globalization, in terms of trade agreements, the creation of economic and socio-economic blocs, geopolitical constellations and the emergence of developing economies.

The development has generated an essential need for both comprehending and transmitting employee relations issues within the international, as well as the national, context. Although cultural perspectives have been considered as a variable in understanding 
different national employee systems, particularly in the significant field embracing management studies, there have been no recent publications focusing specifically on language and culture. There is, of course, an increasing necessity for this perspective as the interconnectivity of economies, driven by globalization, demands an understanding of comparative employee systems based on a more indepth analysis encompassing both language and culture. It is posited that the central mechanism for this is a holistic understanding which requires an intimate link between language and culture.

International impact, which has been a driving force on institutions, employee relations actors, ideologies and the broader socio-economic frameworks, such as corporatism and varieties of capitalism, for example, has created the dynamism for change. In this respect, the book provides an insight into the dynamics of shifting cultural and translation factors, the former adapting and the following expanding concepts and terminologies.

The book ascertains the language and cultural characteristics contributing to an understanding of translation issues in international comparative employee relations. To facilitate this in a conceptual model, for comprehension and pragmatic application in the broad area of comparative employee relations, this is synthesized from selected existing conceptual models. Allowing both discussion and explanation of language and cultural factors, as related to employee relations in the international context, and consequently provide the basis of more in-depth analysis and interpretation of employee relations in different national contexts.

\section{LANGUAGE AND CULTURE IN THE INTERNATIONAL CONTEXT}

The globalized world with its diversity of multilingual societies has stimulated recent research interest focused on the relationship and efficacy of language and culture. There has, of course, always been recognition and understanding of the intimate link between language and culture and this connection has been investigated from many disciplinary perspectives. Recent research, however, has increasingly had its genesis in multi- and interdisciplinary approaches, creating conceptual research models on which methodological strategies can be evolved. 
The significance of language and culture has accelerated during the last decades as a consequence of globalization and in particular the demands of the broad areas of economics and finance, business, management, innovation and technology for the internalization of mutual communication and understanding. Globalization in the broadest sense is, of course, nothing new. What is new is the rate of acceleration of the factors impacting on the phenomenon of globalization: the shifting boundaries of politics, of global institutions, economic connectivity, the definitions of internationalism and global relations, and the overarching issues of resources and environmentalism.

The mechanisms facilitating the complex intercourse of these relationships are numerous but two factors are critical: First, the continuous technological advancement of the Internet and associated communication developments and, second, the medium of communication, language. The latter has two aspects. First, the phenomenon of English as a global language and, second, the essential connection this has to other languages. It is paramount that language and culture are not viewed as separate entities but as a mutual dependent unit of analysis which is defined by the specific register under investigation.

Placing this understanding in the international context demonstrates that language and culture are essential components of nation-states' international competitiveness and, therefore, the comprehension of correct technical terminology across and in between languages has to be viewed from a broad perspective.

Further evidence for these perspectives can be derived from the data used by the World Economic Forum (2018) to construct an international comparative index measuring the performance of individual nation states in the global economic environment. The Global Competitiveness Index 4.02018 is based on a substantial number of performance criteria for each country or economic region, inclusive of cultural determinants predetermined in areas such as education and ability to innovate. It, therefore, integrates macroeconomic and micro business aspects, the latter including public and private institutions, health and infrastructure. The result engenders one index which reflects the competitiveness, and the productivity and efficiency, of the region or country. The index provides a useful tool for identifying critical variables in the economic and social matrix of nation states.

This analysis allows deductions on what particular combinations of variables add to incremental international competitive advantages 
Table I.1 The Global Competitive Index 4.02018 rankings

\begin{tabular}{lcc}
\hline Economy & Rank & Score, Scale: 0-100 \\
\hline United States & 1 & 85.6 \\
Singapore & 2 & 83.5 \\
Germany & 3 & 82.8 \\
Switzerland & 4 & 82.6 \\
Japan & 5 & 82.5 \\
Netherlands & 6 & 82.4 \\
Hong Kong SAR & 7 & 82.3 \\
United Kingdom & 8 & 82.0 \\
Sweden & 9 & 81.7 \\
Denmark & 10 & 80.6 \\
Australia & 14 & 78.9 \\
China & 28 & 72.6 \\
Italy & 31 & 70.8 \\
Nigeria & 115 & 47.5 \\
\hline
\end{tabular}

Note: Covering 140 economies, the Global Competitive Index 4.0 measures national competitiveness - defined as the set of institutions, policies, and factors that determine the level of productivity.

Source: Data adapted and taken from The Global Competitive Report 2018 (World Economic Forum, 2018).

of countries. Table I.1, for example, reveals the concentration of countries in the top of the table, with multilingual societies with educational policies encouraging and nurturing the acquisition of foreign languages, which contribute to their international competitiveness. A closer analysis of the factors used in the Index 4.0 2018 construction also points to the linkages of technology and innovation, for instance, to effective predilections from behavioral attitudes.

Understanding languages is, therefore, indispensable in a comprehensive understanding of contrasting and comparing employee relations within the current international framework. It also raises the question of which languages are predominant in the interconnected global world, a question closely linked to the power languages can exercise. A useful indication is provided by the Power Language Index (PLI), an index constructed from 20 indicators with the aim of measuring the influence of language.

Table I.2 reveals that the top six languages are also the official 
Table I.2 Power Language Index (PLI) ranking for top 10 languages

\begin{tabular}{lccc}
\hline Language & Rank & Score & Native \\
\hline English & 1 & 0.889 & 446.0 \\
Mandarin & 2 & 0.411 & 960.0 \\
French & 3 & 0.337 & 80.0 \\
Spanish & 4 & 0.329 & 470.0 \\
Arabic & 5 & 0.273 & 295.0 \\
Russian & 6 & 0.244 & 150.0 \\
German & 7 & 0.191 & 92.5 \\
Japanese & 8 & 0.133 & 125.0 \\
Portuguese & 9 & 0.119 & 215.0 \\
Hindi & 10 & 0.117 & 310.0 \\
\hline
\end{tabular}

Source: Data adapted from World Economic Forum (2018).

languages of the United Nations. The ranking order of Table I.2 also confirms that English is the most powerful language using the PLI indicators; this is reflected by the fact that of the G7 nations, three, namely the USA, UK and Canada, belong to this category. It furthermore is strengthened by the historical distribution and use of English as the global lingua franca. The interpretation of employee relations terminology in the 'global' English context is highly dependent on the cultural linkage of the specific region, country or specific setting of usage.

Cultural factors can, therefore, be viewed as complex aggregates adding to the broader economic effects of countries, and a specific understanding of these factors provide an incremental international competitive advantage.

\section{EMPLOYEE RELATIONS AND CULTURE IN THE INTERNATIONAL CONTEXT}

The distinctive relationship between culture and global economic developments and trends can be identified, the nation states' economic efficacy gains from an understanding of this and contributes to national wealth.

Specific studies have analyzed aspects of national economic 


\section{Table I.3 Business systems and matching clusters of selected} countries

\begin{tabular}{llll}
\hline Cluster 1 & Cluster 2 & Cluster 3 & Cluster 4 \\
\hline Canada & Germany & Greece & Finland \\
UK & Austria & Turkey & Denmark \\
Australia & Belgium & Portugal & Sweden \\
Switzerland & Ireland & Spain & \\
USA & Netherlands & Hungary & \\
New Zealand & & Slovakia & \\
\hline
\end{tabular}

Source: Data taken and adapted from Hotho (2014).

systems which include cultural characteristics. Thus, for example, Hotho (2014) collected a list of nine variables which included institutional data but also evaluation of 'behavioral' characteristics, such as trust and paternalism, determinants of cultural traits, and applied these to business systems.

Despite the limitations of the number of factors Hotho used as variables, clusters could be constructed which emphasized simple groups of countries sharing arrays of common cultural attributes which distinctly, and significantly, impact on employee relations.

Thus Table I.3 demonstrates that over and above economic organization, institutional arrangements, the predispositions stemming from industrialization processes and socio-political variables, there are differences and similarities in cultural characteristics shaping countries. The significance of the cultural input, focusing, for example, on skills, trust and authority, is illustrated by the following comment on Hotho's findings: '. . . the ways that skills are developed, certified and controlled exert significant influence on prevalent employment relations and work systems, as do the dominant norms governing trust and authority relationships' (Sorge et al., 2015).

A fundamental need to include cultural factors for a full understanding of employee relations is substantiated from the above analysis. However, the identification and definitions used for interpreting cultural characteristics, particularly when translating these between languages, is highly dependent on the specific context, in this case the precise area of employee relations. Importantly, for this book the two main conceptual approaches for the study of culture, the emic and the etic, is not a central issue. Emic analysis assumes that each culture is 
a distinctive entity that can only be studied from inside that culture, whereas etic analysis assumes that there are cultural universals, and consequently cultural characteristics which can be categorized, as illustrated in Table I.3, across different cultures. What is suggested here is a holistic approach where the etic and emic methods, as described by $\mathrm{Lu}$ (2012), are synthesized, allowing language, culture and translation concepts and practices to be viewed within one conceptual framework.

\section{LANGUAGE AND CULTURE AND THE TRANSLATION FOCUS}

The pragmatic application of language and cultural perceptions are particularly significant and intimately linked to the process of translation. In the case of employee relations, this is implicitly understood but not always subject to analysis. Blanpain and Blake correctly identified that this is linked to the specific understanding of realities: 'one of the main difficulties, which presents a real pitfall for the comparative scholar, is the fact that identical words in different languages might have different meanings, while the corresponding terms may embrace wholly different realities' (Blanpain and Blake, 2010: 16).

Language does indeed have much bearing on comparative research, for contrasting highly differentiated notions entails knowledge of both the systems under scrutiny and the language of the countries covered. This holds even truer in the domains referred to above, where most terminology identifying practices and institutions is frequently crafted out of negotiation processes. After all, the battle of ideas is often carried out through a battle of words (Hyman, 2007) instantiated in collective bargaining, social dialogue, and concertation; this might lead one to assume that linguistic problems in comparative analysis bear relevance only at the highest levels of abstraction.

Yet this is far from the case, especially in today's labor market, where massive changes in global migration patterns have generated a growing multilingual and multicultural workforce. Misinterpretations of rules and practices cross-linguistically might give rise to ambiguities and confusion as regards workers' union rights, health and safety, and working conditions. One might argue that the use of English as a lingua franca might facilitate understanding when comparing and contrasting national institutions cross-linguistically. Yet this is far from the case, even when comparative analysis of industrial relations 
practices involves countries making use of the same language (Hyman, 2005: 204). More generally, 'linguistic standardization due to the universal use of English is not always matched by a similarity of structures and functions' (Tiraboschi, 2003: 192).

Accordingly, language plays a major role at the time of contrasting industrial relations and labor law notions cross-nationally. For this reason, Hyman and Gumbrell-McCormick warn us that 'serious comparative research requires the capacity at least to read the languages of the countries covered' (Hyman and GumbrellMcCormick, 2013: viii). While this is certainly true, it is likewise important to understand how and what to compare. Blanpain and Blake stated clearly 'in order to compare what is, in fact, comparable; one needs to compare the functions institutions perform rather than institutions themselves' (Blanpain and Blake, 2010: 16).

A number of scholars from different disciplines (social sciences, translation studies, industrial relations) have closely examined the problems resulting from transposing concepts and institutions in different languages. Barring a few exceptions (Bromwich, 2006; Manzella, 2015), scant consideration has been given to languagerelated issues in IR and, specifically, to translation issues arising at the time of comparing and contrasting different IR practices. This might be due, at least in part, to the fact that IR terminology is often regarded as being part of the legal discourse. While this might be true, the terminology that is peculiar to this domain is frequently the result of interactions in collective bargaining and talks between actors involved in negotiations, to the extent that 'the subject has developed its own language' (Green, 1994: 2), leading one to speak of a discursive genre per se, which deserves further analysis. The relevance of the cultural dimension at the time of comparing industrial relations practices cross-linguistically has also been neglected. Meardi speaks of 'the neglect of culture by comparative industrial relations ... Culture has left aside, as a convenient "emergency" variable, to account for the "unexplained residua" (Meardi, 2011: 336). Recently, Manzella and Koch (2017) have made an attempt in stressing the significance of culture, and its close relationship with language, in understanding context-bound meanings and national labor relations practices.

Failing to consider the cultural dimension in translating employee relations practices might result in misleading interpretations of industrial relations concepts when transposing institutions from one language into the other. 
The book is thus an attempt to integrate the cultural and translation factors to enable those involved with international dimensions of employee relations to be aware of system differentials at a deeper level of understanding. Specifically, the book addresses 'interlingual translation', which according to Pym is concerned with the 'rewording between languages' (Pym, 2014) and with how culture affects comprehension of industrial relations concepts and institutions in this transposition process.

\section{THE STRUCTURE OF THE BOOK}

The book is divided into two parts, the first offering an overview of employee relations in the global context and providing a conceptual structure for the language and culture aspect; a central focus for the chapters in the book. The second part provides an analysis, from a selected number of countries, where aspects of language and cultural perspectives are included. Given the diversity of the latter aspects, the book provided guidelines for the individual chapters but did not posit a prescribed framework; particularly in part II, the approach for the selected countries was left to the authors.

\section{Part I: Comparative Employee Relations in Context}

Underlying any discussion concentrating on the international dimension of employee relations is the phenomenon of globalization. The concept of globalization encompasses a multitude of processes but at the core is the increasing, and convoluted, integration between nation states, cooperative economic areas, and identifiable geopolitical regions. Employee relations are affected both by the macro level of development where economic consequences have an impact, and the micro level where international enterprise strategies are formulated.

Chapter 1 is a critical examination of how recent global developments have influenced employee relations; market forces and institutions have, in the interconnectivity of the global economy, led to dramatic changes. The chapter draws on original research to emphasize the changes and challenges that employee relations are subjected to, referring to selected countries, Denmark for example, as well as individual businesses, such a Ryanair and Google.

Chapter 2 has a specific focus on contextual differences between 
employee relations in different countries and reflects on the changing nature of work, which is undergoing extraordinary transformations and reshaping global employment relations. A central theme of the chapter is the role language plays in identifying how individual countries have a symbiotic relationship between language use in employee relations and practice.

To accommodate the cultural and language elements in describing and understanding these multifaceted features in an international comparative context requires a conceptual model.

Chapter 3 proposes that central to such a model is the relationship between culture and language. The role of culture, in particular, is examined and adapted to incorporate the specific semantic field of employee relations, but also to be aware of the broader related aspects of the economy, management, and business. In this respect, Chapter 3 proposes a dynamic model, expanding current theories underlying the analysis of cross-cultural research, and suggesting that a new approach, reciprocal augmentation between culture and language, can construct a bridge across the language and cultural differences between countries. In practice, the mutual enrichment of culture and language provides a holistic dimension to the process of translation which is essential for a more profound analysis and understanding of employee relations in the international context.

\section{Part II: Employee Relations in the National Context}

Part II includes the analysis of a number of countries and their employee relations systems, pointing out cases where cultural and linguistic aspects have a bearing in the conception and understanding of employee relations practices and ideologies. Chapter 4 starts with an examination of China's case, where difficulties arise when conveying the very concept of employee relations, with the local culture that has contributed to the creation of specific employee relation concepts (e.g. 'harmony,' 'iron rice bowl'). The chapter places the language and culture synthesis advocated in the book, into an explanation of the development of Chinese employee relations in the larger socio-economic framework. What emerges is that Chinese language and culture hold unique characteristics, with underlying concepts, for example harmony, which is crucial for the understanding of Chinese employee relations.

Chapter 5, focusing on Italy, considers the notion of a 'gangmaster' 
to emphasize the role of translation in cross-national comparison and the intertwined relationship between language, culture, and law in the broad field of employee relations.

Chapter 6 considers the national system of plant-level employee representation in Germany, and the issues resulting from rendering specific terms in other languages, in this case focusing on the German works council, and thus acknowledging the cultural complexities that this exercise might generate. The German works council has been a particularly widespread model for employee representation, and therefore its language and cultural embedment in German employee relations is especially noteworthy.

The focus then, in Chapter 7, turns to the USA and the increasing ideologically driven divergence within the country between left-leaning 'equity and voice' states and right-leaning 'individual rights and efficiency' states. The chapter emphasizes the critical importance of terminology in employee relations and highlights the continued prominence of context and regional culture within the USA. Developing economies are increasingly influencing global economic developments and Chapter 8 centers in Nigeria. Nigeria's system of employee relations is discussed, as are the links between culture and labor relations, with a focus on the role of English and local languages in negotiations. A distinct focus of the chapter is how contextual factors, the broader socio-economic and political system, of the evolving economy, have an interdependent relationship with cultural prerogatives which are shaping the actors and institutions pertinent for employee relations.

The concluding Chapter 9 constitutes an attempt to summarize the findings gathered in this book and to point out that translation and language form part of interactions and relationships through which 'bundles of employment relational practices' are understood and performed. Such an approach will perhaps gain a better understanding of similarities and differences in employee relations, serving the purpose of comparative research.

\section{BIBLIOGRAPHY}

Blanpain, R., Bisom-Rapp, S., Corbett, W. R., Josephs, H. K. and Zimmer, M. J. 2007. The Global Workplace: International and Comparative Employment Law, Cambridge: Cambridge University Press. 
Blanpain, R. and Blake, J. 2010. Comparative Labour Law and Industrial Relations in Industrialized Market Economies, the Netherlands: Kluwer International.

Bromwich, W. 2006. Lessico negoziale, contesto culturale e processi comunicativi nello sciopero nei servizi essenziali a New York. Diritto Delle Relazioni Industriali, 2(XVI), pp.414 4.

Frege, C. and Kelly, J. 2013. Comparative Employment Relations in the Global Economy, London and New York: Routledge.

Green, G. D. 1994. Industrial Relations Texts and Case Studies (4th edn), London: Pitman Publishing.

Hotho. J. 2014. From typology to taxonomy: a configurational analysis of business systems and their explanatory power. Organization Studies, 35 , pp. 671-702.

Hyman, R. 2005. Words and things: the problem of particularistic universalism. In Barbier, J. C. and Letablier, M. (eds), Comparaisons internationales des politiques sociales, enjeux épistémologiques et méthodologiques/ Cross-national Comparison of Social Policies: Epistemological and Methodological Issues, pp. 191-208, Brussels: Peter Lang.

Hyman, R. 2007. How can trade unions act strategically? Transfer: European Review of Labour and Research, 13(2), pp. 193-210.

Hyman, R. and Gumbrell-McCormick, R. 2013. Trade Unions in Western Europe: Hard Times, Hard Choices, Oxford: Oxford University Press.

Lu, Lung-Tan. 2012. 'Etic or emic'? Measuring culture in international business research. International Business Research, 5(5), pp. 109-15.

Manzella, P. 2015. Lost in translation: language and cross-national comparison in industrial relations. The E-Journal of International and Comparative Labour Studies, 4(1), pp. 1-21. Retrieved on 9 July 2019 from http://ejcls. adapt.it/index.php/ejcls_adapt/article/view/260/0.

Manzella, P. and Koch. K. 2017. Legal and cultural implications in managing multilingual and multicultural labor: selected translation issues from the US National Labor Relations Board. Lebende Sprachen, 62(1), pp. 59-78.

Meardi, G. 2011. Understanding trade union cultures. Industrielle Beziehungen, 18(4), pp. 336-45.

Pym, A. 2014. Exploring Translation Theories, Routledge: Abingdon.

Singam, P. and Koch, K. 1994. Industrial relations: problems of German concepts and terminology for the English translator. Lebende Sprachen, XXXIX(1), pp. 158-62.

Sorge, A., Noordherhaven, N. and Koen, C. 2015. Comparative International Management, London and New York: Routledge.

Tiraboschi, M. (ed.) 2003. Marco Biagi: Selected Writings, the Netherlands: Kluwer Law International.

World Economic Forum 2018. The Global Competitive Report 2018, Geneva: World Economic Forum. 